\title{
Epidemiology and Potential Pathomechanisms of Cardiovascular Comorbidities in Psoriasis: A Report from the GRAPPA 2010 Annual Meeting
}

\author{
WOLF-HENNING BOEHNCKE
}

\begin{abstract}
There is increasing awareness that psoriasis is more than "skin deep." Several recent reviews focused on biomarkers have indicated the systemic dimension of psoriasis and the comorbidity that psoriasis shares with other chronic inflammatory diseases. Of emerging significance is the relationship to cardiovascular disease, which contributes substantially to patients' increased mortality. This article examines currently available evidence favoring the concept of a causal link between psoriasis and cardiovascular disease, and summarizes a report represented at the 2010 Annual Meeting of GRAPPA (Group for Research and Assessment of Psoriasis and Psoriatic Arthritis). (J Rheumatol 2012;39:441-4; doi:3899/jrheum.111245)
\end{abstract}

Key Indexing Terms:

ADIPOKINE ATHEROSCLEROSIS INSULIN RESISTANCE

This paper includes ideas presented previously by Prof. Dr. Boehncke in another publication: Boehncke WH, et al. The 'psoriatic march': A concept of how severe psoriasis may drive cardiovascular morbidity. Exp Dermatol 2011;20:303-7.

Epidemiology and the Concept of the "Psoriatic March" There is increasing awareness that psoriasis is more than skin deep and that it has important systemic manifestations that are shared with other chronic inflammatory diseases, such as rheumatoid arthritis ${ }^{1}$. Of emerging significance is the relationship between cardiovascular disease and severe psoriasis, which may explain the increased rate of mortality in patients with psoriasis ${ }^{2}$. The diagnosis "severe psoriasis" in this context refers to all patients who at any point in time received either systemic therapy or phototherapy or were treated on an inpatient basis ${ }^{3}$. As many as one-third of all patients with psoriasis meet these criteria ${ }^{4}$.

Cardiovascular comorbidity is well known to rheumatologists, because it occurs in patients with rheumatoid arthritis $^{5,6}$ or psoriatic arthritis (PsA) ${ }^{7}$. When trying to dissect the relative contribution of PsA and coexisting psoriasis, Gladman, et al determined that high scores on the Psoriasis Area and Severity Index (which measures activity and

From the Department of Dermatology, Johann Wolfgang Goethe-University, Frankfurt am Main, Germany.

Prof. Boehncke has received honoraria as a speaker or advisor for Abbott, Biogen Idec, Essex, Janssen-Cilag, and Pfizer. He has acted as a consultant for Abbott, Serono, Schering-Plough, Pfizer (formerly Wyeth), and Janssen-Cilag, and is currently supported by unrestricted research grants from Abbott and Janssen-Cilag.

W-H. Boehncke, $M D$.

Address correspondence to Prof. W-H. Boehncke, Department of Dermatology, Johann Wolfgang Goethe-University, Theodor-Stern-Kai 7 , D-60590 Frankfurt am Main, Germany.

E-mail: boehncke@em.uni-frankfurt.de
ENDOTHELIAL CELL DYSFUNCTION PSORIASIS severity of psoriasis of the skin) are major predictors for cardiovascular disease ${ }^{8}$.

Associations do not per se establish a causal relationship between disorders, but the concept of psoriasis as an independent cardiovascular risk factor is gaining support. In Sweden, an increased cardiovascular mortality was observed among psoriasis inpatients (probably with more severe disease), but not in outpatients ${ }^{9}$. Additionally, a recent population-based study identified severe psoriasis as an independent risk factor for myocardial infarction ${ }^{3}$, and a case-control study showed substantially elevated levels of coronary artery calcification as an indicator for coronary artery disease among inpatients with psoriasis compared to controls matched for all major known cardiovascular risk factors ${ }^{10}$. Other studies found the adjusted odds ratio of developing myocardial infarction for patients with psoriasis to range from 1.6 to $1.86^{11,12}$.

One must acknowledge that patients with severe psoriasis appear to have an excess of "traditional" risk factors for the development of cardiovascular disease ${ }^{13}$. A recent review outlined a scenario on how psoriasis unfolds from gene to clinic ${ }^{5}$, with comorbidity "likely...result[ing] from chronic inflammation." Another study describes the cascade of events leading to type 2 diabetes mellitus, given initial findings on insulin resistance among patients with psoria$\operatorname{sis}^{14}$ (the "psoriatic march," Figure 1$)^{15}$. The present article examines the currently available evidence to support causality of this cascade in psoriasis.

\section{Severe Psoriasis Is Associated with Elevated Biomarkers} Indicating a State of Systemic Inflammation

Several biomarkers indicating systemic inflammation have been shown to be elevated in psoriasis patients. These include adipokines, i.e., cytokines produced by adipo-

Personal non-commercial use only. The Journal of Rheumatology Copyright $\subset$ $(2012$. All rights reserved. 

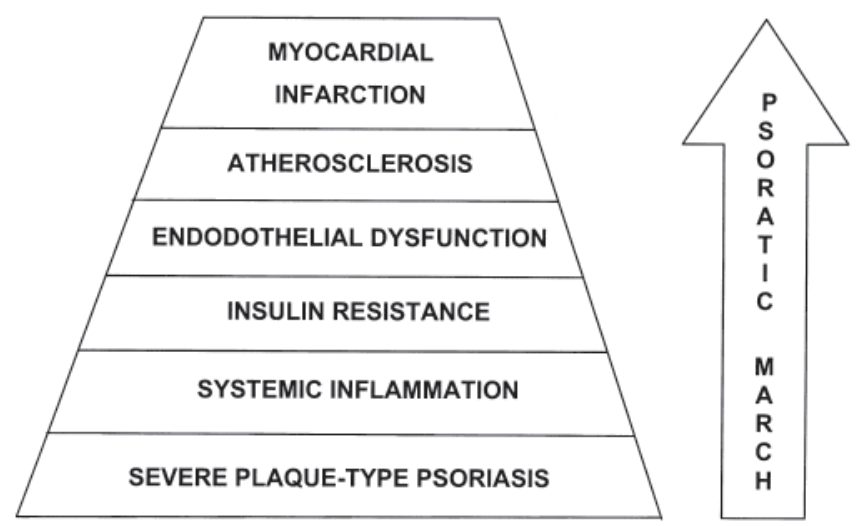

Figure 1. The concept of the "psoriatic march" suggests a causal link between psoriasis as a systemic inflammatory condition and cardiovascular comorbidity, as systemic inflammation may cause insulin resistance, which in turn triggers endothelial cell dysfunction, subsequently leading to atherosclerosis and finally myocardial infarction or stroke.

cytes $^{14,15}$, C-reactive protein ${ }^{16}$, vascular endothelial growth factor ${ }^{17}$, and indicators of platelet activation such as P-selectin ${ }^{18,19}$. Of note, the adipokine milieu in the blood of psoriasis patients is strikingly similar to that in prediabetic individuals who exhibit signs of insulin resistance. A recent study, analyzing tissue fluid collected though microdialysis, documented the same diabetes-like micromilieu in lesional psoriatic $\operatorname{skin}^{20}$.

\section{Systemic Inflammation Induces Insulin Resistance}

Insulin resistance, i.e., reduced uptake of glucose by metabolically active cells upon exposure to insulin, is reflected at the clinical level by the homeostasis model assessment of insulin resistance ${ }^{20}$. A more sensitive test for insulin resistance is the oral glucose tolerance test. Using these methods, 2 cross-sectional studies showed that psoriasis patients exhibit insulin resistance at clinical levels ${ }^{14,21}$.

The notion of insulin being a vasoactive hormone is of particular relevance: intravenously administered insulin enhances blood flow and vasodilation in a nitric oxide (NO)-dependent manner ${ }^{22}$. This pathway involves activation of phosphoinositide 3-kinase and leads to phosphorylation of endothelial NO synthase; it is therefore related to the pathway mediating insulin's metabolic effects. However, insulin may also activate the proatherogenic mitogen-activated protein kinase pathway in endothelial cells ${ }^{23}$.

\section{Insulin Resistance Triggers Endothelial Cell Dysfunction} Endothelial cell dysfunction refers to an imbalance in release of vasodilating and vasoconstricting factors. When this balance is changed, it predisposes the endothelium toward an atherogenic milieu, which may cause rolling of leukocytes, smooth muscle growth, impaired coagulation, vascular inflammation, atherosclerosis, and thrombosis ${ }^{24}$. In atherosclerotic coronary arteries, vasodilation is impaired and a paradoxical constriction may occur, suggestive of endothelial cell dysfunction ${ }^{25}$. Several lines of evidence provide links between insulin resistance and endothelial cell dysfunction, particularly the insulin receptor substrate-1 (IRS-1). IRS-1 is one of the key proteins downstream of the insulin receptor for signaling metabolic effects, e.g., glucose uptake in fat cells and NO production in endothelial cells. Low cellular IRS-1 identifies individuals who are markedly insulin-resistant and exhibit evidence of early atherosclero$\operatorname{sis}^{26}$. Moreover, low IRS-1 expression may be a marker for not only insulin resistance but also arterial stiffness ${ }^{27}$. These data imply that shared stressors, such as hyperglycemia, cause oxidative stress and downregulation of IRS-1 in fat cells and endothelial cells, leading to insulin resistance and endothelial cell dysfunction.

In psoriasis, several groups found evidence for endothelial cell dysfunction, using ultrasound methods; in particular, flow-mediated dilation was impaired $28,29,30,31$.

\section{Endothelial Cell Dysfunction Drives Atherosclerosis}

As stated above, a change in the balance of vasodilating and vasoconstricting factors predisposes the endothelium toward atherosclerosis, which is now regarded as an inflammatory disease ${ }^{32}$. Early events comprise adhesionmediated leukocyte extravasation, which is facilitated by activated platelets and followed by infiltrating macrophages, releasing cytokines and enzymes such as matrix metalloproteinases, thus degrading the connective tissue matrix. This step is followed by the formation of a more advanced fibrous lesion with accumulating lipid-rich necrotic debris and smooth muscle cells. This fibrous-capped plaque then develops into an advanced and very complex lesion. Continuing inflammation may alter the fibrous cap to create an unstable plaque, rupture of which would cause thromboembolic complications, such as myocardial infarction or stroke.

\section{Toward a Concept for Comprehensive Monitoring of Patients with Severe Psoriasis}

It is still unclear if the relationships discussed here are really causal in nature. However, the epidemiological data reveal that patients with severe psoriasis often have comorbidity, most importantly premature cardiovascular disease. Management of patients with severe psoriasis therefore requires more than the assessment and treatment of skin symptoms alone $e^{15,33}$.

Recently, the National Psoriasis Foundation published screening recommendations for psoriasis patients ${ }^{34}$. The cardiovascular comorbidity recommendations are derived from the American Heart Association, but they do not include psoriasis itself as an independent risk factor for cardiovascular diseases. However, another publication does define target ranges for patients with psoriasis, with specific characteristics depending on the number of additional cardiovascular risk factors (Table 1$)^{35}$.

Personal non-commercial use only. The Journal of Rheumatology Copyright $\subset$ C 2012. All rights reserved. 
Table 1. A checklist to monitor psoriasis patients for cardiovascular risk factors.

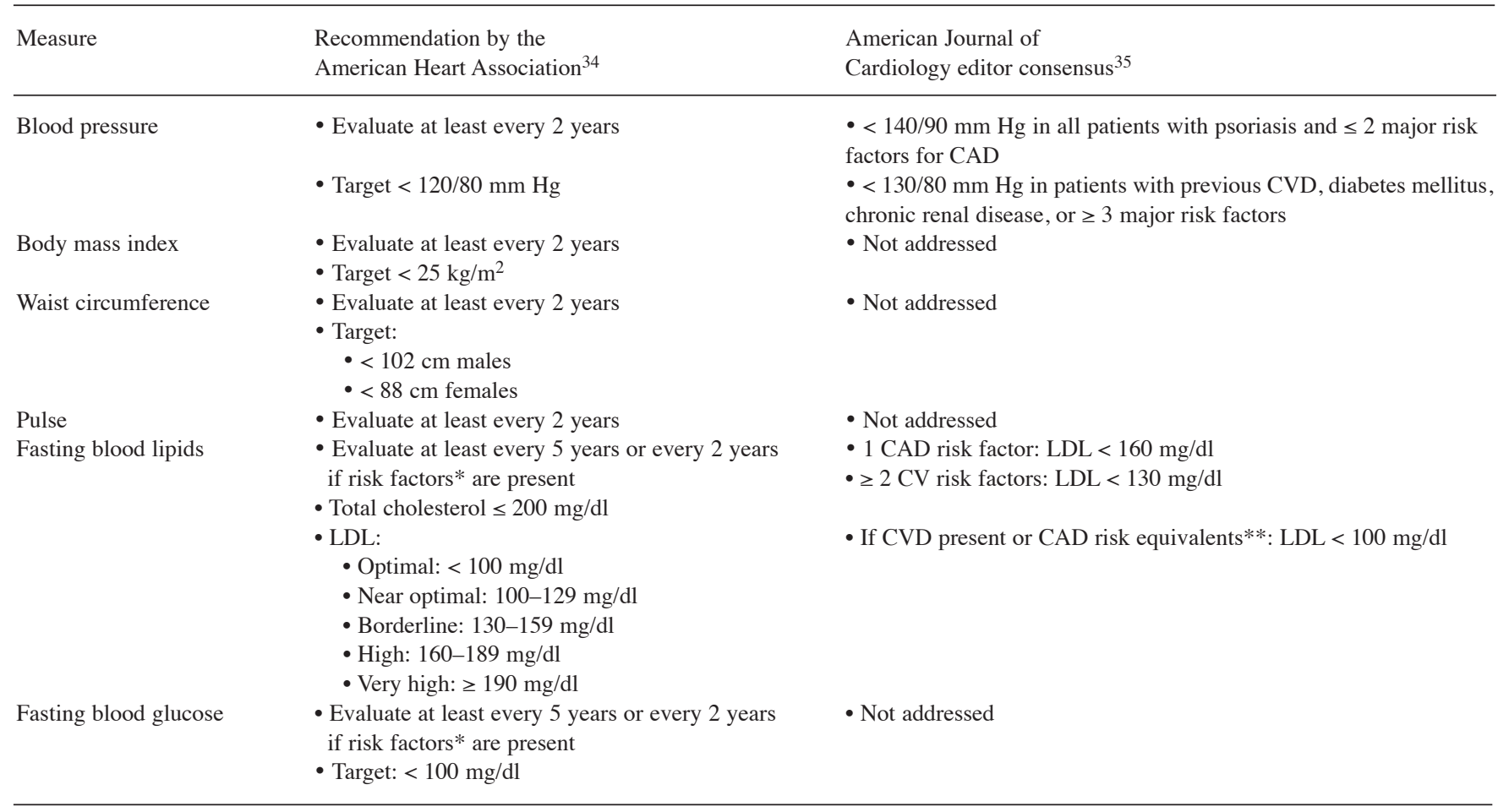

* e.g., positive family history, presence of diabetes, smoking; ** e.g., diabetes. CAD: coronary artery disease; CVD: cardiovascular disease.

In an example of the benefits of more comprehensive psoriasis treatment, obese patients with moderate to severe psoriasis had a better response to low-dose cyclosporine in a controlled clinical trial if a calorie-reduced diet was included in their treatment regimen ${ }^{36}$.

Whether the psoriatic march can be stopped through early continuous systemic therapy has been addressed indirectly in 2 retrospective analyses: one shows that longterm continuous methotrexate treatment reduces cardiovascular morbidity among psoriasis patients ${ }^{37}$; the other documents reduction of C-reactive protein as a biomarker for cardiovascular risk in a registrational study with the tumor necrosis factor- $\alpha$-blocking biologic etanercept ${ }^{38}$. Several prospective studies have directly addressed this question and demonstrated that successful continuous systemic antipsoriatic therapy ameliorates biomarkers for cardiovascular risk, including cytokines, adipokines, and endothelial cell dysfunction ${ }^{39,40,41,42}$.

Table 2. Summary of evidence suggesting or opposing psoriasis as an independent cardiovascular risk factor.

$\begin{aligned} & \text { Psoriasis IS an independent } \\ & \text { cardiovascular risk factor }\end{aligned}$
Psoriasis is NOT an independent
cardiovascular risk factor

Dose effect ${ }^{3,9}$

More coronary artery calcification ${ }^{10}$

Odds ratio for CVD 1.6-1.8 $8^{11,12} \quad$ Normal cardiovascular risk ${ }^{43}$

Insulin resistance ${ }^{14,21,22}$

Endothelial dysfunction ${ }^{28-31} \quad$ Normal endothelial function ${ }^{44}$

CVD: cardiovascular disease.

\section{Conclusion}

The concept of psoriasis being causally related to cardiovascular comorbidity, i.e., organ-specific inflammation driving atherosclerosis, is supported by an increasing number of studies (Table 2). More efforts at the level of both clinical and basic research are needed to develop a foundation upon which we can base a comprehensive approach to the management of psoriasis. This will remain an important topic for ambitious scientists in cutaneous biology and related fields for years to come.

\section{REFERENCES}

1. Nestle FO, Kaplan DH, Barker J. Psoriasis. N Engl J Med 2009;361:496-509.

2. Gelfand JM, Troxel AB, Lewis JD, Kurd SK, Shin DB, Wang X, et al. The risk of mortality in patients with psoriasis: Results from a population-based study. Arch Dermatol 2007;143:1493-9.

3. Gelfand JM, Neimann AL, Shin DB, Wang X, Margolis DJ, Troxel $\mathrm{AB}$. Risk of myocardial infarction in patients with psoriasis. JAMA 2006;296:1735-41.

4. Schon MP, Boehncke WH. Psoriasis. N Engl J Med 2005; 352:1899-912.

5. Myasoedova E, Gabriel SE. Cardiovascular disease in rheumatoid arthritis: A step forward. Curr Opin Rheumatol 2010;22:342-7.

6. Khan F, Galarraga B, Belch JJ. The role of endothelial function and its assessment in rheumatoid arthritis. Nat Rev Rheumatol 2010;6:253-61.

7. Peters MJ, van der Horst-Bruinsma IE, Dijkmans BA, Nurmohamed MT. Cardiovascular risk profile of patients with spondylarthropathies, particularly ankylosing spondylitis and psoriatic arthritis. Semin Arthritis Rheum 2004;34:585-92.

8. Gladman DD, Ang M, Su L, Tom BD, Schentag CT, Farewell VT.

Personal non-commercial use only. The Journal of Rheumatology Copyright $\subset$ 2012 . All rights reserved. 
Cardiovascular morbidity in psoriatic arthritis. Ann Rheum Dis 2009;68:1131-5.

9. Mallbris L, Akre O, Granath F, Yin L, Lindelof B, Ekbom A, et al. Increased risk for cardiovascular mortality in psoriasis inpatients but not in outpatients. Eur J Epidemiol 2004;19:225-30.

10. Ludwig RJ, Herzog C, Rostock A, Ochsendorf FR, Zollner TM, Thaci D, et al. Psoriasis: A possible risk factor for development of coronary artery calcification. Br J Dermatol 2007;156:271-6.

11. Brauchli YB, Jick SS, Miret M, Meier CR. Psoriasis and risk of incident myocardial infarction, stroke or transient ischaemic attack: An inception cohort study with a nested case-control analysis. Br J Dermatol 2009;160:1048-56.

12. Prodanovich S, Kirsner RS, Kravetz JD, Ma F, Martinez L, Federman DG. Association of psoriasis with coronary artery, cerebrovascular, and peripheral vascular diseases and mortality. Arch Dermatol 2009;145:700-3.

13. Poikolainen K, Karvonen J, Pukkala E. Excess mortality related to alcohol and smoking among hospital-treated patients with psoriasis. Arch Dermatol 1999;135:1490-3.

14. Boehncke S, Thaci D, Beschmann H, Ludwig RJ, Ackermann H, Badenhoop K, et al. Psoriasis patients show signs of insulin resistance. Br J Dermatol 2007;157:1249-51.

15. Boehncke WH, Boehncke S, Schon MP. Managing comorbid disease in patients with psoriasis. BMJ 2010;340:b5666.

16. Coimbra S, Oliveira H, Reis F, Belo L, Rocha S, Quintanilha A, et al. C-reactive protein and leucocyte activation in psoriasis vulgaris according to severity and therapy. J Eur Acad Dermatol Venereol 2010;24:789-96.

17. Detmar M, Brown LF, Claffey KP, Yeo KT, Kocher O, Jackman $\mathrm{RW}$, et al. Overexpression of vascular permeability factor/vascular endothelial growth factor and its receptors in psoriasis. J Exp Med 1994;180:1141-6.

18. Ludwig RJ, Schultz JE, Boehncke WH, Podda M, Tandi C, Krombach F, et al. Activated, not resting, platelets increase leukocyte rolling in murine skin utilizing a distinct set of adhesion molecules. J Invest Dermatol 2004;122:830-6.

19. Garbaraviciene J, Diehl S, Varwig D, Bylaite M, Ackermann H, Ludwig RJ, et al. Platelet P-selectin reflects a state of cutaneous inflammation: Possible application to monitor treatment efficacy in psoriasis. Exp Dermatol 2010;19:736-41.

20. Salgo R, Thaci D, Boehncke S, Diehl S, Hofmann M, Boehncke WH. Microdialysis documents changes in the micromilieu of psoriatic plaques under continuous systemic therapy. Exp Dermatol 2011;20:130-3.

21. Ucak S, Ekmekci TR, Basat O, Koslu A, Altuntas Y. Comparison of various insulin sensitivity indices in psoriatic patients and their relationship with type of psoriasis. J Eur Acad Dermatol Venereol 2006;20:517-22.

22. Scherrer U, Randin D, Vollenweider P, Vollenweider L, Nicod P. Nitric oxide release accounts for insulin's vascular effects in humans. J Clin Invest 1994;94:2511-5.

23. Kim JA, Montagnani M, Koh KK, Quon MJ. Reciprocal relationships between insulin resistance and endothelial dysfunction: Molecular and pathophysiological mechanisms. Circulation 2006;113:1888-904.

24. Verma S, Anderson TJ. Fundamentals of endothelial function for the clinical cardiologist. Circulation 2002;105:546-9.

25. Ludmer PL, Selwyn AP, Shook TL, Wayne RR, Mudge GH, Alexander RW, et al. Paradoxical vasoconstriction induced by acetylcholine in atherosclerotic coronary arteries. N Engl J Med 1986;315:1046-51.

26. Jansson PA, Pellme F, Hammarstedt A, Sandqvist M, Brekke H, Caidahl K, et al. A novel cellular marker of insulin resistance and early atherosclerosis in humans is related to impaired fat cell differentiation and low adiponectin. FASEB J 2003;17:1434-40.
27. Sandqvist M, Nyberg G, Hammarstedt A, Klintland N, Gogg S, Caidahl K, et al. Low adipocyte IRS-1 protein expression is associated with an increased arterial stiffness in non-diabetic males. Atherosclerosis 2005;180:119-25.

28. Gisondi P, Fantin F, Del Giglio M, Valbusa F, Marino F, Zamboni $\mathrm{M}$, et al. Chronic plaque psoriasis is associated with increased arterial stiffness. Dermatology 2009;218:110-3.

29. Ulusoy RE, Karabudak O, Yokusoglu M, Kilicaslan F, Kirilmaz A, Cebeci BS. Noninvasive assessment of impaired endothelial function in psoriasis. Rheumatol Int 2010;30:479-83.

30. Karadag AS, Yavuz B, Ertugrul DT, Akin KO, Yalcin AA, Deveci $\mathrm{OS}$, et al. Is psoriasis a pre-atherosclerotic disease? Increased insulin resistance and impaired endothelial function in patients with psoriasis. Int J Dermatol 2010;49:642-6.

31. Balci DD, Balci A, Karazincir S, Ucar E, Iyigun U, Yalcin F, et al. Increased carotid artery intima-media thickness and impaired endothelial function in psoriasis. J Eur Acad Dermatol Venereol 2009;23:1-6.

32. Hansson GK. Inflammation, atherosclerosis, and coronary artery disease. N Engl J Med 2005;352:1685-95.

33. Boehncke WH, Boehncke S, Tobin AM, Kirby B. The 'psoriatic march': A concept of how severe psoriasis may drive cardiovascular comorbidity. Exp Dermatol 2011;20:303-7.

34. Kimball AB, Gladman D, Gelfand JM, Gordon K, Horn EJ, Korman NJ, et al. National Psoriasis Foundation clinical consensus on psoriasis comorbidities and recommendations for screening. J Am Acad Dermatol 2008;58:1031-42.

35. Friedewald VE, Cather JC, Gelfand JM, Gordon KB, Gibbons GH, Grundy SM, et al. AJC editor's consensus: psoriasis and coronary artery disease. Am J Cardiol 2008;102:1631-43.

36. Gisondi P, Del Giglio M, Di Francesco V, Zamboni M, Girolomoni G. Weight loss improves the response of obese patients with moderate-to-severe chronic plaque psoriasis to low-dose cyclosporine therapy: A randomized, controlled, investigator-blinded clinical trial. Am J Clin Nutr 2008;88:1242-7.

37. Prodanovich S, Ma F, Taylor JR, Pezon C, Fasihi T, Kirsner RS. Methotrexate reduces incidence of vascular diseases in veterans with psoriasis or rheumatoid arthritis. J Am Acad Dermatol 2005;52:262-7.

38. Strober B, Teller C, Yamauchi P, Miller JL, Hooper M, Yang YC, et al. Effects of etanercept on C-reactive protein levels in psoriasis and psoriatic arthritis. Br J Dermatol 2008;159:322-30.

39. Coimbra S, Oliveira H, Reis F, Belo L, Rocha S, Quintanilha A, et al. Circulating adipokine levels in Portuguese patients with psoriasis vulgaris according to body mass index, severity and therapy. J Eur Acad Dermatol Venereol 2010;24:1386-94.

40. Coimbra S, Oliveira H, Reis F, Belo L, Rocha S, Quintanilha A, et al. Interleukin (IL)-22, IL-17, IL-23, IL-8, vascular endothelial growth factor and tumour necrosis factor-alpha levels in patients with psoriasis before, during and after psoralen-ultraviolet $\mathrm{A}$ and narrowband ultraviolet B therapy. Br J Dermatol 2010;163:1282-90.

41. Boehncke S, Salgo R, Garbaraviciene J, Beschmann H, Hardt K, Diehl S, et al. Effective continuous systemic therapy of severe plaque-type psoriasis is accompanied by amelioration of biomarkers of cardiovascular risk: Results of a prospective longitudinal observational study. J Eur Acad Dermatol Venereol 2011;25:1187-93.

42. Boehncke S, Fichtlscherer S, Salgo R, Garbaraviciene J, Beschmann H, Diehl S, et al. Systemic therapy of plaque-type psoriasis ameliorates endothelial cell function: Results of a prospective longitudinal pilot trial. Arch Dermatol Res 2011;303:381-8.

Personal non-commercial use only. The Journal of Rheumatology Copyright $\subset$ ( 2012. All rights reserved. 